Article

\title{
Surface Modification of Esophageal Stent Materials by a Drug-Eluting Layer for Better Anti-Restenosis Function
}

\author{
Yuxin Bai ${ }^{1}$, Kun Zhang ${ }^{1, *}$, Ru Xu ${ }^{1}$, Hongtao Liu ${ }^{1}$, Fangxia Guan ${ }^{1}$, Huiwen Luo ${ }^{2}$, Ye Chen ${ }^{2}$ and \\ Jingan $\mathrm{Li}^{2}$,* iD \\ 1 School of Life Science, Zhengzhou University, Zhengzhou 450000, China; 13037597362@163.com (Y.B.); \\ 18341349663@163.com (R.X.); liuht1230@126.com (H.L.); guanfangxia@126.com (F.G.) \\ 2 School of Materials Science and Engineering, Zhengzhou University, Zhengzhou 450000, China; \\ ab19961116abc@163.com (H.L.); chenyecx@126.com (Y.C.) \\ * Correspondence: zhangkun@zzu.edu.cn (K.Z.); lijingan@zzu.edu.cn (J.L.)
}

Received: 5 April 2018; Accepted: 31 May 2018; Published: 6 June 2018

\begin{abstract}
It is generally accepted that stent implantation is the mainstream therapy in clinics for esophageal cancer in the later period. However, the restenosis caused by tumor cells, epithelial cells, and fibroblasts seriously interferes with the stent medical application and limits its long-term services. To address this conundrum, a series of drug-eluting stents were invented and verified to be feasible in the early stage after implantation, but the limited drug loading and good cell compatibility of the stent materials may lead to more serious restenosis and further endanger the patient's life. In previous work, we modified the esophageal stent material 317L stainless steel (317L SS) surface with a poly-dopamine/poly-ethylenimine layer (PDA/PEI), which had strong anti-tumor functions. In this contribution, we employed a usual drug in clinic, 5-fluorouracil (5-Fu), with series of density onto the PDA/PEI modified 317L SS to investigate the influence of 5-Fu immobilization on the anti-restenosis function. The surface characterization including 5-Fu quantity, atomic force microscopy (AFM). Water contact angle measurement indicated successful preparation of the PDA/PEI/5-Fu layers. The spectrophotometric characterization revealed that the immobilized 5-Fu rapidly released over $24 \mathrm{~h}$. However, the Eca109, Het-1A, and L929 cells culture results suggested that the released 5-Fu made a significant contribution to improving the apoptosis and necrosis of these pathological cells, and the PDA/PEI/5-Fu layers maintain the consistent anti-restenosis function on their surfaces with the PDA/PEI layer after $24 \mathrm{~h}$. All the results demonstrated the PDA/PEI/5-Fu layers' excellent ability to suppress esophageal tumor cells, epithelial cells, and fibroblasts, suggesting a potential application on the surface modification of esophageal stents for better anti-restenosis function.
\end{abstract}

Keywords: esophageal stent materials; anti-restenosis; functional layer; poly-dopamine; 5-fluorouracil; poly-ethylenimine

\section{Introduction}

Esophageal cancer is a malignant tumor of the digestive tract in esophageal epithelial tissue. It is highly difficult to cure globally and has a high mortality ratio (only 10\%-15\% survival ratio) within five years [1-3]. Metal stent implantation is generally accepted as the crucial method for relieving late esophageal obstruction in nonsurgical palliative care [4] and the stent types include fully covered stents, bare metal stents, and drug-eluting stents [5]. Fully covered stents have a high migration rate and are therefore removed with 8 weeks of placement of the stents, while chemotherapy and radiation therapy has to be given in the meantime to shrink the tumor so that they may not need the stents. Bare metal stents are permanent stents and hence are not the preferred stents, unlike fully 
covered metal stents. Drug-eluting stents are predominantly used for uncovered stents and this is for a minority of patients who do not tolerate chemotherapy and radiation therapy. Although esophageal drug-eluting stents have the advantage of a certain anti-restenosis function through the release of the loaded drug for in situ therapy [6-8], the drug loading on the stent surface is limited, and the stent's anti-restenosis function will gradually lose potency with the drug release [9]. In addition, after the drug release is over, the exposed stent materials, which generally have good biocompatibility, will not only reduce the stent's property of suppressing malignant cells, but also promote their adhesion and excessive proliferation, and this unfavorable for the long-term efficacy of stents [10]. Therefore, it is desirable to develop functional modified layers on continuous anti-restenosis.

Layer by layer polymer modification technique is an effective surface modification method for endowing the materials specific functions. Each modified layer can be prepared onto the materials surface with different molecules to achieve different purposes: a poly-dopamine (PDA) layer is usually deposited onto the materials surface as the "double faced adhesive tape" to bind the functional molecules to the materials [11], while poly-ethylenimine (PEI) has been proven to suppress cancer cells in much research [12]. In the previous work, we developed a poly-dopamine/poly-ethylenimine modified layer (PDA/PEI) with strong functions in suppressing esophageal tumor cells [12]. Nevertheless, the PDA/PEI layer's effects on esophageal epithelial cells and fibroblast have still not been investigated because the esophageal restenosis is usually formed by the interaction of the esophageal tumor cells, epithelial cells, and fibroblast [13]. In addition, the PDA/PEI as drug-eluting carrier on the esophageal stent materials (usually 317L stainless steel, 317L SS) should also be considered [14]. 5-fluorouracil (5-Fu) is an effective anti-cancer drug that is widely applied in clinics through the administration of oral, topical, injection, and stent elution [15]. Thus, in this contribution, we immobilized the 5-Fu drug onto the PDA/PEI modified 317L SS surface to investigate the PDA/PEI/5-Fu layers' anti-restenosis function, including suppressing the hypermorphosis of malignant esophageal tumor cells, epithelial cells, and fibroblast.

\section{Materials and Methods}

\subsection{Immobilizing 5-Fu onto the PDA/PEI Layer}

The PDA film was deposited on mirror-polished 317L stainless steel (317L SS) substrates ( $\Phi 10 \mathrm{~mm}$, Shaanxi Xi'an-Baoji 317L stainless steel pipe factory, Baoji, China) in the reaction solution at $25^{\circ} \mathrm{C}$ [16]. The reaction solution was obtained by dissolving dopamine hydrochloride $(1 \mathrm{mg} / \mathrm{mL})$ into Tris buffer ( $\mathrm{pH}$ 8.5). After deposition for $2.5 \mathrm{~h}$, the samples were washed in deionized water $\left(\mathrm{dH}_{2} \mathrm{O}\right)$. The as-deposited coatings were subsequently tempered at $120^{\circ} \mathrm{C}$ for $1 \mathrm{~h}$ under $5 \times 10^{-4} \mathrm{~Pa} .2 .6 \mathrm{mg} / \mathrm{mL}$ of poly-ethylenimine (PEI, Sigma, Ontario, CA, USA) with optimized molecular weight (MW) of $7 \times 10^{4} \mathrm{Da}$ in the previous work was prepared in the $\mathrm{dH}_{2} \mathrm{O}$ [12]. Then, the 317L SS coated with PDA were immersed into the above PEI solution for incubation. After reaction for $2 \mathrm{~h}$, the specimens were washed with $\mathrm{dH}_{2} \mathrm{O}$ ( 3 times, $\left.5 \mathrm{~min}\right)$ and dried for further preparation [12]. The drug 5-fluorouracil (5-Fu, Sigma, Ontario, CA, USA) was dissolved in dimethyl sulphoxide (DMSO, Sigma, Ontario, CA, USA) with a concentration of $50 \mathrm{mg} / \mathrm{mL}$, and diluted with gradient concentration of 2, 1.8, 1.6, 1.4 and $1.2 \mathrm{mg} / \mathrm{mL}$ in Tris-HCl buffer. Finally, the PDA/PEI coated 317L SS were immersed into the above 5-Fu solution and incubated for $24 \mathrm{~h}$, followed with the washing step before surface analysis. The samples were labeled as PDA/PEI/5-Fu-1, PDA/PEI/5-Fu-2, PDA/PEI/5-Fu-3, PDA/PEI/5-Fu-4 and PDA/PEI/5-Fu-5, respectively.

\subsection{Characterization of PDA/PEI/5-Fu Layers}

The amounts of immobilized 5-Fu on the PDA/PEI/5-Fu layers and their eluting drug at 1,3, 6, 12 and $24 \mathrm{~h}$ were determined by typical spectrophotometry [17]. The surface morphology and roughness of samples were analyzed by atomic force microscopy (AFM, 7500, Key sight, Santa Rosa, CA, USA) [18]. To evaluate the wettability of the PDA/PEI/5-Fu layers, the water contact angles 
(WCA) of the 317L SS, PDA, PDA/PEI, PDA/PEI/5-Fu-1, PDA/PEI/5-Fu-2, PDA/PEI/5-Fu-3, PDA/PEI/5-Fu-4 and PDA/PEI/5-Fu-5 samples were detected by a contact angle apparatus (DSA 100, Krüss, GmbH, Hamburg, Germany) [19]. To investigate the modified layers' biomechanical properties, the stress values of each sample were detected by a microcomputer controlled electronic universal testing machine (WDW_200, Shanghai Hualong testing instrument Limited by Share Ltd., Shanghai, China). The weight loss of all the samples was also measured to evaluate the layers' biodegradability properties [20].

\subsection{Anti-Restenosis Function of PDA/PEI/5-Fu Layers}

To investigate the influence of the released 5-Fu on anti-esophageal-restenosis function of the PDA/PEI/5-Fu layers, the Eca109 (Esophageal carcinoma), Het-1A (Human esophageal epithelial cells) and L929 (Fibroblast) cell lines preserved in our laboratory were seeded on the culture-plates at a density of $2 \times 10^{4}$ cells $/ \mathrm{mL}$ respectively and cultured in an incubator at $37^{\circ} \mathrm{C}$ and $5 \% \mathrm{CO}_{2}$ for 1 day to simulate the esophageal-restenosis microenvironment, and then PDA/PEI/5-Fu-1, PDA/PEI/5-Fu-2, PDA/PEI/5-Fu-3, PDA/PEI/5-Fu-4, PDA/PEI/5-Fu-5, PDA/PEI, PDA and 317L SS samples were immersed in to the culture medium (not contact with the cells) for 1, 3, 6 and $12 \mathrm{~h}$, respectively [21]. The operation process of 5-Fu release affecting cell behavior was displayed in Figure 1. After that, a cell-permeable acridine orange (AO) in combination with a plasma membrane-impermeable DNA-binding dye propidium iodide (PI) was used to detect apoptosis or necrosis of Eca109 cells, Het-1A cells and L929 cells. AO and PI excite green and red fluorescence respectively when they are intercalated into DNA. Only AO but not PI can cross the plasma membrane of normal cell. Late apoptotic and necrotic cells take up the two dyes and show a predominant orange fluorescence. The cells were stained with a 1:1 mixture of AO $(100 \mathrm{mg} / \mathrm{mL})$ and PI $(100 \mathrm{mg} / \mathrm{mL})$ at $37^{\circ} \mathrm{C}$ for $5 \mathrm{~min}$, and then immediately inspected in a fluorescence microscope. Criteria for identification are the following: (a) green intact nucleus, vital cells; (b) dense green areas of chromatin condensation in the nucleus, early apoptosis; (c) dense orange areas of chromatin condensation, late apoptosis; and (d) orange intact nucleus, secondary necrosis [22].
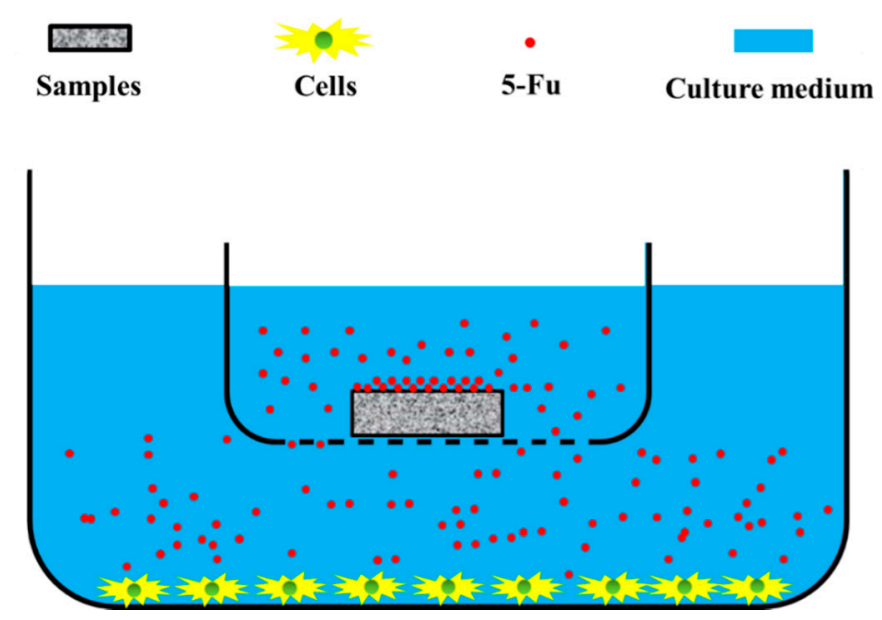

Figure 1. The scheme of 5-fluorouracil (5-Fu) released from the modified layers and their effect on cells.

To further investigate the PDA/PEI/5-Fu layers' anti-esophageal-cancer function of the PDA/PEI layer, the Eca109, Het-1A and L929 cells were directly seeded on the surfaces of the PDA/PEI/5-Fu-1, PDA/PEI/5-Fu-2, PDA/PEI/5-Fu-3, PDA/PEI/5-Fu-4, PDA/PEI/5-Fu-5, PDA/PEI, PDA and 317L SS samples at a density of $2 \times 10^{4}$ cells $/ \mathrm{mL}$, and cultured in standard condition for $4 \mathrm{~h}, 1$ day and 3 days, respectively [23]. Their apoptosis or necrosis was also evaluated by the AO/PI staining and the statistical analysis. 


\subsection{Statistical Analysis}

The data were statistically evaluated using ANOVA by homogeneity test of variances firstly, and post hoc test was prepared subsequently in LSD method for comparison. They were expressed as mean \pm standard deviation (SD). The probability value $p<0.05$ was considered as a significant difference. The data analysis was performed using the software SPSS 11.5 (SPSS Company, Chicago, IL, USA).

\section{Results and Discussion}

\subsection{Quantity of Immobilized 5-Fu}

To confirm the successful immobilization of 5-Fu onto the PDA/PEI layer, quantitative characterization for 5-Fu density on the PDA/PEI/5-Fu-1, PDA/PEI/5-Fu-2, PDA/PEI/5-Fu-3, $\mathrm{PDA} / \mathrm{PEI} / 5-\mathrm{Fu}-4$ and PDA/PEI/5-Fu-5 surfaces were performed, and the results were presented in Figure 2. The density of immobilized 5-Fu presented decreased trend as: PDA/PEI/5-Fu-1 > PDA/PEI/5-Fu-2 > PDA/PEI/5-Fu-3 > PDA/PEI/5-Fu-4 > PDA/PEI/5-Fu-5, which was consistent with the 5-Fu solution concentration. The density ranged from about $5 \mu \mathrm{g} / \mathrm{mm}^{2}$ to about $10 \mu \mathrm{g} / \mathrm{mm}^{2}$, indicating successful immobilization of the 5-Fu drug onto the PDA/PEI surface.

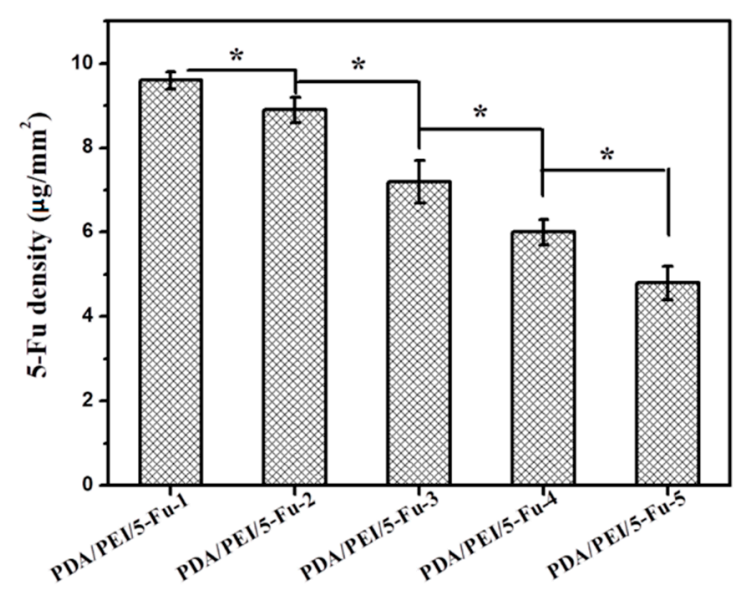

Figure 2. Surface 5-Fu density of $\mathrm{PDA} / \mathrm{PEI} / 5-\mathrm{Fu}-1, \mathrm{PDA} / \mathrm{PEI} / 5-\mathrm{Fu}-2, \mathrm{PDA} / \mathrm{PEI} / 5-\mathrm{Fu}-3$, $\mathrm{PDA} / \mathrm{PEI} / 5-\mathrm{Fu}-4$ and PDA/PEI/5-Fu-5 samples $\left({ }^{*} p<0.05\right.$, mean $\left.\pm \mathrm{SD}, n=3\right)$.

\subsection{AFM and Wettability}

Figure 3A shows the morphology and roughness of the PDA/PEI/5-Fu-1, PDA/PEI/5-Fu-2, PDA/PEI/5-Fu-3, PDA/PEI/5-Fu-4, PDA/PEI/5-Fu-5, PDA/PEI, PDA and 317L SS samples detected by the AFM characterization. The 317L SS substrate presented a rough surface with the roughness of $4.2 \pm 1.6 \mathrm{~nm}$. The PDA deposition made the 317L SS surface smoother $(2.4 \pm 1.0 \mathrm{~nm})$, which was consistent with the reported work elsewhere [24,25]. The PDA/PEI surface showed rougher surfaces with the roughness of $6.5 \pm 2.2 \mathrm{~nm}$, while the significantly increased roughness occurred after the 5-Fu immobilization, with a trend of: PDA/PEI/5-Fu-1 $(18.7 \pm 6.9 \mathrm{~nm})$ and PDA/PEI/5-Fu-2 $(24.0 \pm 6.5 \mathrm{~nm})$ $>$ PDA $/ \mathrm{PEI} / 5-\mathrm{Fu}-3(11.0 \pm 2.7 \mathrm{~nm})>\mathrm{PDA} / \mathrm{PEI} / 5-\mathrm{Fu}-4(6.0 \pm 1.4 \mathrm{~nm})$ and PDA $/ \mathrm{PEI} / 5-\mathrm{Fu}-5(6.0 \pm 2.9 \mathrm{~nm})$. Wherein, the PDA/PEI/5-Fu-4 and PDA/PEI/5-Fu-5 samples made little roughness change compared with the PDA/PEI layer, which may be attributed to their lesser amount of the immobilized 5-Fu.

Water contact angle was measured to examine the wettability of the PDA/PEI/5-Fu-1, PDA/PEI/5-Fu-2, PDA/PEI/5-Fu-3, PDA/PEI/5-Fu-4, PDA/PEI/5-Fu-5, PDA/PEI, PDA and 317L SS surfaces (Figure 3B). Compared with 317L SS, water contact angles increased after coated with PDA, while dramatically decreased after the PEI immobilized, indicating that the PDA/PEI layer were more hydrophilic than PDA and 317L SS surfaces, while the 5-Fu immobilization made the 
water contact angles increased again and exhibited a trend as: PDA/PEI/5-Fu- $1\left(49.0^{\circ} \pm 2.5^{\circ}\right)$ $<\mathrm{PDA} / \mathrm{PEI} / 5-\mathrm{Fu}-2\left(60.5^{\circ} \pm 1.9^{\circ}\right)$ and PDA/PEI/5-Fu-3 $\left(64.8^{\circ} \pm 2.4^{\circ}\right)<\mathrm{PDA} / \mathrm{PEI} / 5-\mathrm{Fu}-4\left(78.8^{\circ} \pm 3.3^{\circ}\right)$ $<\mathrm{PDA} / \mathrm{PEI} / 5-\mathrm{Fu}-5\left(86.0^{\circ} \pm 3.0^{\circ}\right)$, which was negatively correlated with the surface roughness, and the previous work also reported that the rough surface may contribute to hydrophilicity $[26,27]$. In summary, all the samples' surfaces showed relative hydrophilic property (water contact angle $<90^{\circ}$ ), and this is preferable for implanted biomaterials [28,29].

(A)

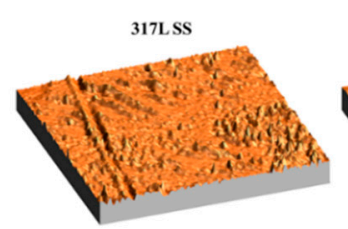

$4.2 \pm 1.6 \mathrm{~nm}$

PDA/PEI/5-Fu-2

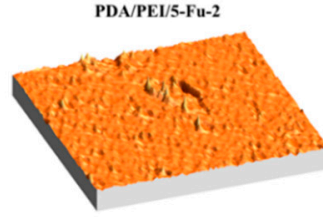

$24.0 \pm 6.5 \mathrm{~nm}$

(B)

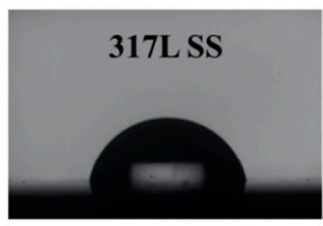

$79.0 \pm 1.5^{\circ}$

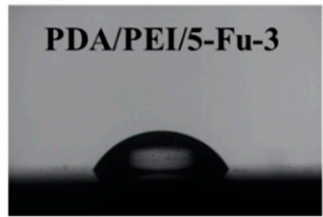

$60.5 \pm 1.9^{\circ}$

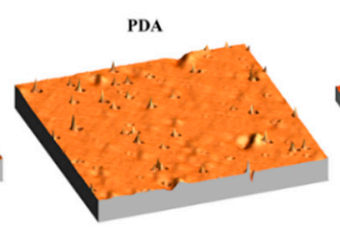

$2.4 \pm 1.0 \mathrm{~nm}$

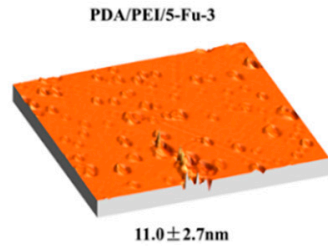

$11.0 \pm 2.7 \mathrm{~nm}$

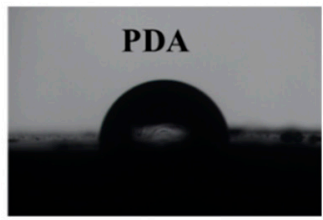

$85.8 \pm 0.6^{\circ}$

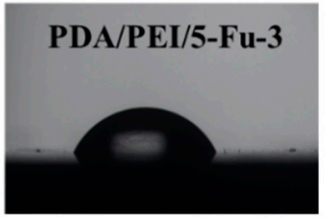

$64.8 \pm 2.4^{\circ}$

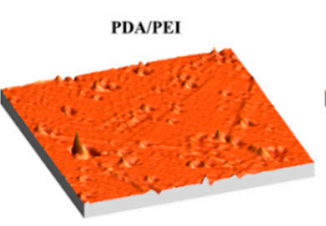

$6.5 \pm 2.2 \mathrm{~nm}$

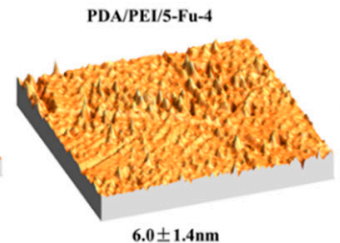

$6.0 \pm 1.4 \mathrm{~nm}$

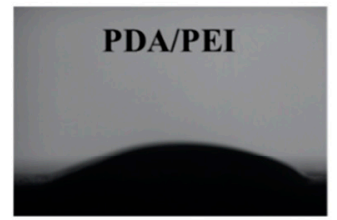

$33.8 \pm 1.7^{\circ}$

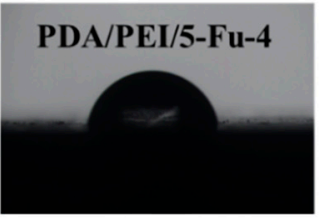

$78.8 \pm 3.3^{\circ}$

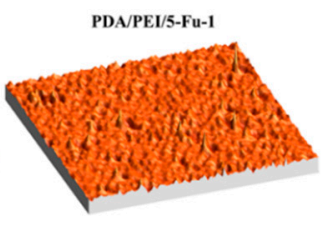

$18.7 \pm 6.9 \mathrm{~nm}$

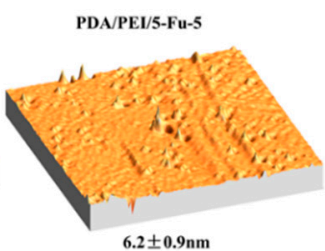

$6.2 \pm 0.9 \mathrm{~nm}$

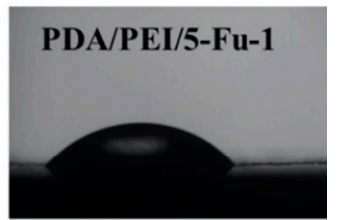

$49.0 \pm 2.5^{\circ}$

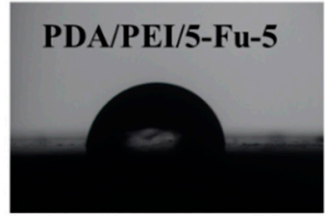

$86.0 \pm 3.0^{\circ}$

Figure 3. (A) Atomic force microscopy (AFM) images and (B) water contact measurement of PDA/PEI/5-Fu-1, PDA/PEI/5-Fu-2, PDA/PEI/5-Fu-3, PDA/PEI/5-Fu-4, PDA/PEI/5-Fu-5, PDA/PEI, PDA and 317L SS.

\subsection{5-Fu Release and the Layers' Biodegradability}

We detected the 5-Fu release of each sample via typical spectrophotometry, and the results showed that the drug rapidly released over within $24 \mathrm{~h}$, more than $60 \%$ of the immobilized 5-Fu was released within $12 \mathrm{~h}$ (Figure 4A). The rapid release of the 5-Fu drug from the surface may have contributed to a stronger anti-cancer and anti-restenosis functions of the implanted esophageal carcinoma stents, but it need to be verified by further cell culture experiments. The biodegradability of each modified layer was also investigated by detecting their weight loss (Figure 4B): the results presented consistent trend with the 5 -Fu release, about $80 \%$ of the PDA/PEI/5-Fu layers weight lost within $24 \mathrm{~h}$ which was attributed to the released 5-Fu, while the PDA/PEI and PDA layers showed a very small value on their weight loss $(<1 \%)$, indicating rapid release of the loaded 5-Fu and good stability of the left PDA/PEI layer. 

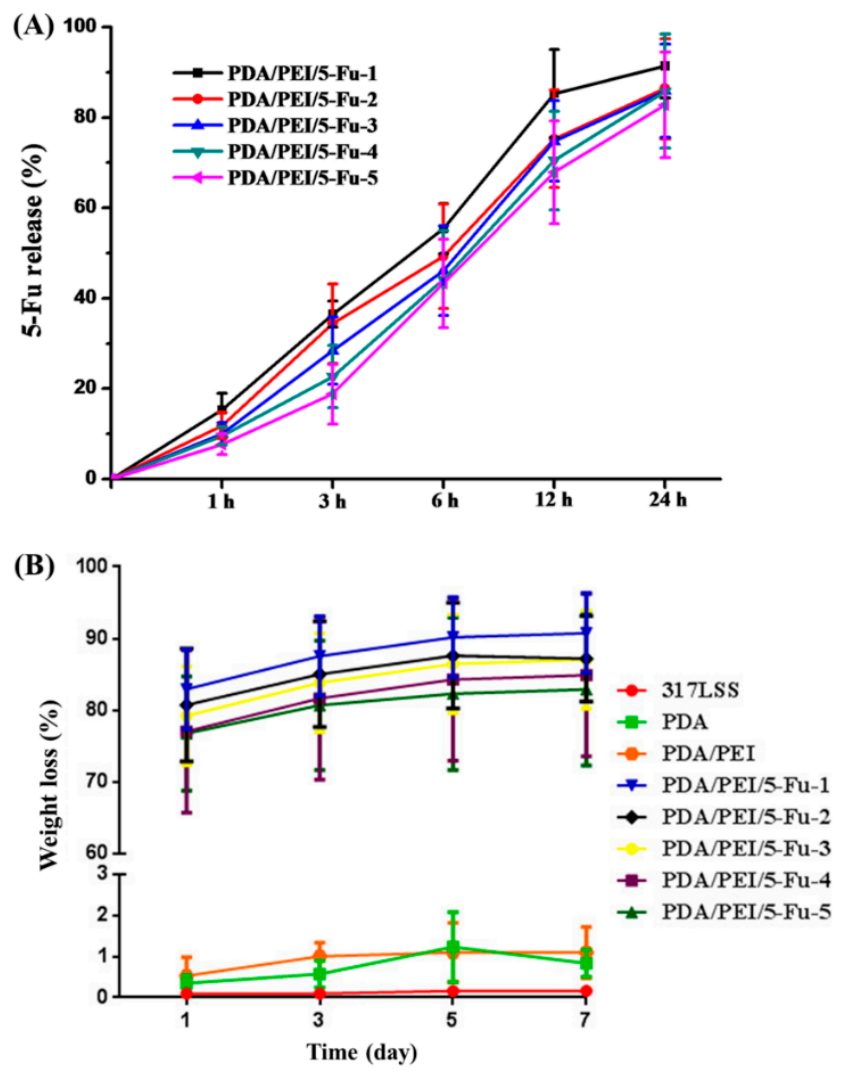

Figure 4. (A) 5-Fu release from the PDA/PEI/5-Fu-1, PDA/PEI/5-Fu-2, PDA/PEI/5-Fu-3, $\mathrm{PDA} / \mathrm{PEI} / 5-\mathrm{Fu}-4$ and PDA/PEI/5-Fu-5 surfaces within $24 \mathrm{~h}$ (mean $\pm \mathrm{SD}, n=5$ ); (B) Weight loss of the PDA/PEI/5-Fu-1, PDA/PEI/5-Fu-2, PDA/PEI/5-Fu-3, PDA/PEI/5-Fu-4, PDA/PEI/5-Fu-5, PDA/PEI, PDA and 317L SS samples after immersed in the PBS for 1 day, 3 days, 5 days and 7 days respectively.

\subsection{The Layers' Biomechanical Properties}

The esophageal stents surface will withstand pressure from the wall of the esophagus after implantation, while traditional modified method (covering) may reduce the stress tolerance and further lead to a high migration rate, thus endowing the modified layer consistent or similar stress tolerance with the base material is crucial for the stents development. In this study, the biomechanical properties of each sample were evaluated by examining their surface stress (Figure 5): all the modified layers showed similar maximum stress values compared with the 317L SS substrate which is a commonly used material for esophageal stent, wherein the PDA/PEI/5-Fu-1 layer showed a consistent maximum stress value (412 MPa) with the 317L SS (416 MPa), suggesting better biomechanical property compared with other modified layers. 


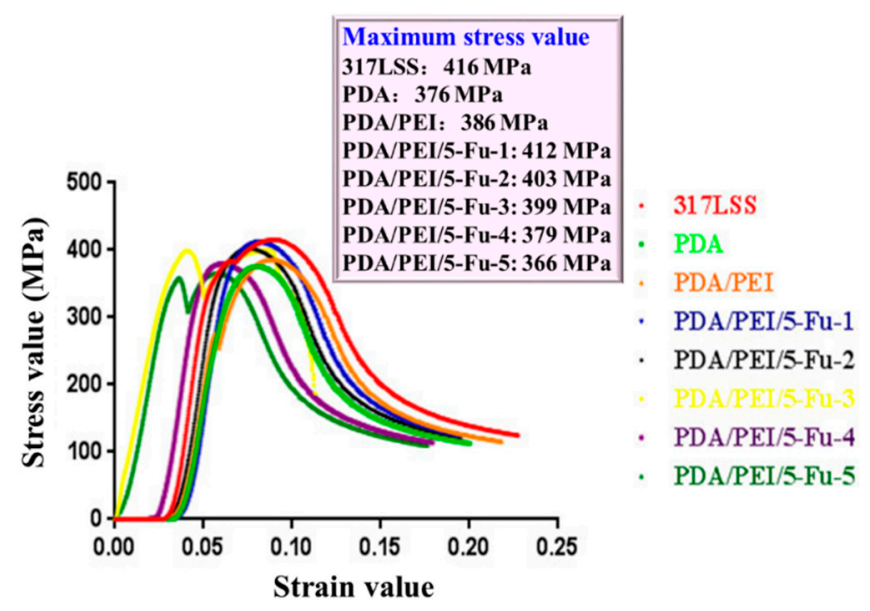

Figure 5. Biomechanical properties of the PDA/PEI/5-Fu-1, PDA/PEI/5-Fu-2, PDA/PEI/5-Fu-3, PDA/PEI/5-Fu-4, PDA/PEI/5-Fu-5, PDA/PEI, PDA and 317L SS surfaces.

\subsection{Effects of Released 5-Fu on Restenosis Related Cells' Apoptosis and Necrosis}

In the late stage of esophageal carcinoma, the $2 / 3$ circumference of the esophagus is infiltrated by cancer and the esophageal tumor cells, fibroblasts, and epithelial cells in the cancer microenvironment cause esophageal stenosis [30,31]. Although the stent implantation may treat the stenosis and maintain the patency of the esophagus within a short time, the cancer microenvironment still exists and will induce esophageal lumen restenosis [32,33]. Thus, loading anti-cancer drug on the stents and endowing the stents strong anti-cancer properties via drug release after implantation became a preferable strategy for esophageal carcinoma treatment. In this work, Eca109 (esophageal tumor cells), Het-1A (epithelial cells), and L929 (fibroblast) cells were cultured on the culture plates to simulate the esophageal-restenosis microenvironment. Each sample was immersed in the culture medium but not contacted with the cells to evaluate the effect of a usual anti-cancer drug (5-Fu) released from the samples surface on restenosis-related cells' apoptosis and necrosis. Figure 6 displayed the immunofluorescence images of AO/PI double stained Eca109 (Figure 6A), Het-1A (Figure 6B) and L929 (Figure 6C) cells. Obviously, 317L SS, PDA and PDA/PEI samples showed no cell loss (apoptosis and necrosis) from 1 to $12 \mathrm{~h}$, all the cells presented green intact nucleus, and this result verified that no 5-Fu was released and further influenced the cells growth and behavior. All the PDA/PEI/5-Fu groups showed drastically decreasing cell numbers within $12 \mathrm{~h}$, which indicated that a significant loss of the pathological cells. In particular, the modified layers loaded with the most 5-Fu (PDA/PEI/5-Fu-1) presented better ability on improving apoptosis and necrosis of the Eca109, Het-1A and L929 cells. A few cells on PDA/PEI/5-Fu-1 exhibited dense orange areas at 1st hour, indicating transition period from early apoptosis to late apoptosis secondary necrosis, and the dense orange areas gradually enlarged with the time went on, almost all the cells showed dense orange areas at the $12 \mathrm{~h}$. Analysis combined with the statistics of cell viability in Figure 7, PDA/PEI/5-Fu-1 group showed lower cell viability ratios compared with the other groups (6.24\% of Eca109, 0\% of Het-1A, and $2.62 \%$ of L929) within $12 \mathrm{~h}$, most of the cells were in the state of apoptosis and necrosis. The results above indicated that the 5-Fu released from the modified layers contributed strong effects on improving the restenosis related cells' apoptosis and necrosis. 


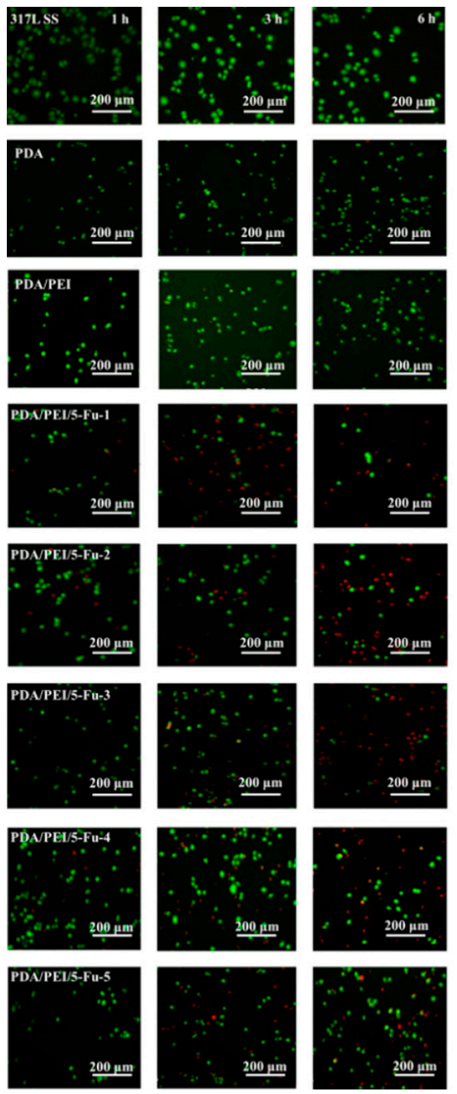

(A)
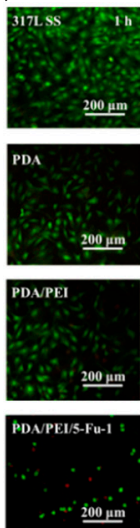

$200 \mu \mathrm{m}$

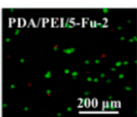

$200 \mathrm{~mm}$

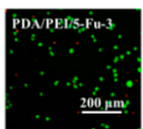

$200 \mathrm{im}$

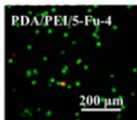

PDAPEU5-Fu-5 "

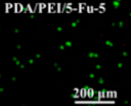

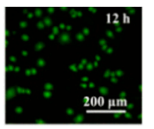
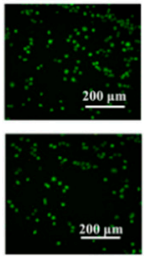

2000
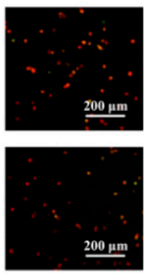

$200 \mu \mathrm{m}$
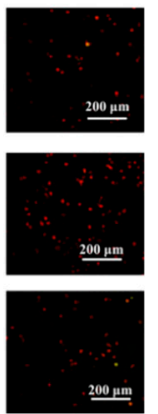

200 min
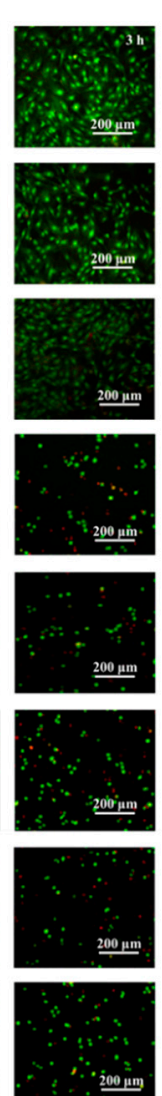
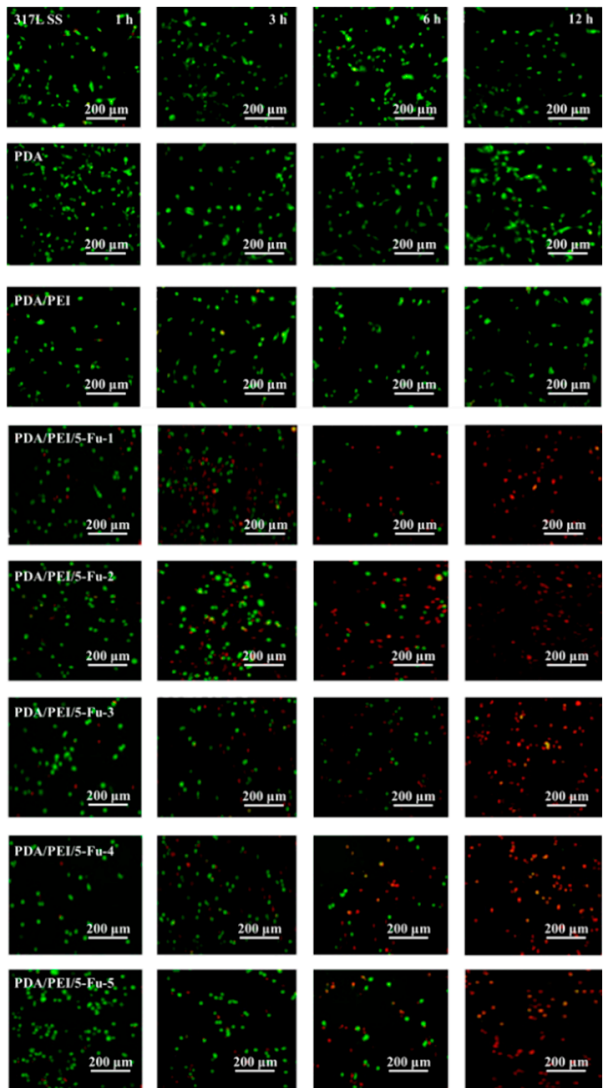

(B)
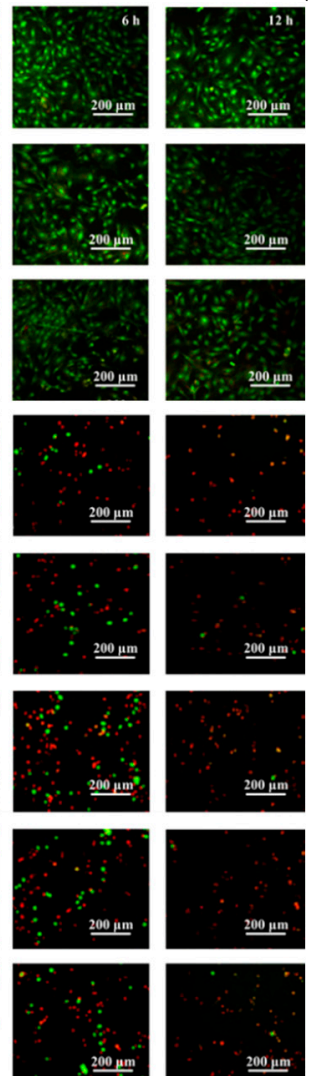

(C)

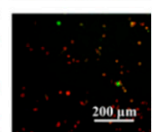

Figure 6. (A) Eca109, (B) Het-1A and (C) L929 cells apoptosis and necrosis influenced by the 5-Fu released from the PDA/PEI/5-Fu layers and reference surfaces (green intact nucleus: vital cells; dense green areas of chromatin condensation in the nucleus: early apoptosis; dense orange areas of chromatin condensation: late apoptosis; orange intact nucleus: secondary necrosis). 

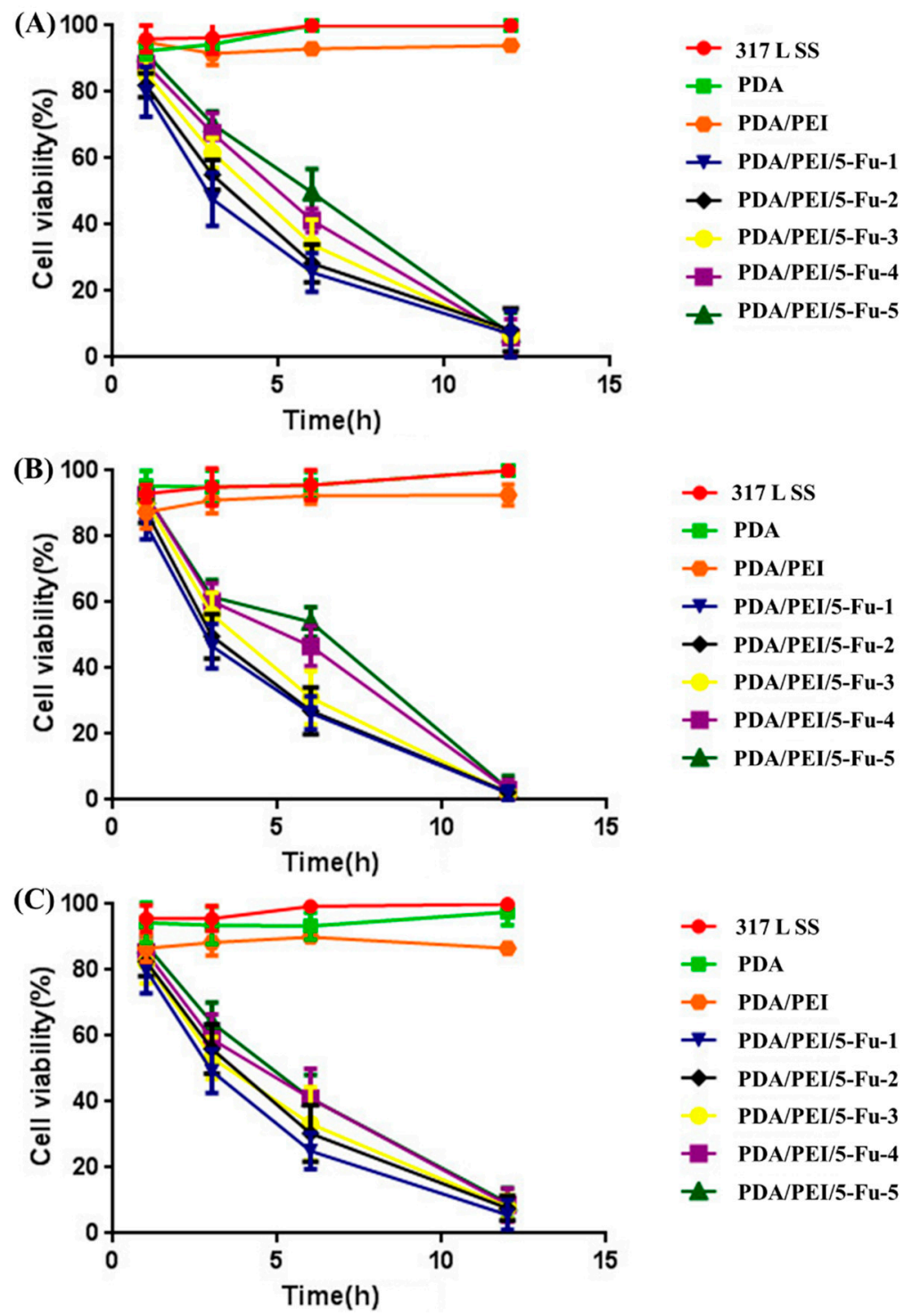

Figure 7. Statistical analysis of (A) Eca109, (B) Het-1A and (C) L929 cells apoptosis and necrosis (by counting cell viability) influenced by the 5-Fu released from the PDA/PEI/5-Fu layers and reference surfaces (mean $\pm \mathrm{SD}, n=3$ ).

\subsection{Effects of PDA/PEI/5-Fu Layers on Restenosis Related Cells' Apoptosis and Necrosis}

After stent implantation, overgrowth of tumor, epithelial, and fibrous tissues at both ends of the stent, or ingrowth along the mesh of the stent, will cause esophageal lumen restenosis [34,35]. Thus, the sustained property of anti-restenosis is crucial for the esophageal stent surface. So, we cultured Eca109 cells, Het-1A and L929 cells on the PDA/PEI/5-Fu surface to investigate their sustained anti-cancer function. Figures 8 and 9 displayed the immunofluorescence images of AO/PI double stained cells and the statistical results. Although there were significant differences between each successive layer on their ability to improve pathological cells' apoptosis and necrosis, both the PDA/PEI/5-Fu and PDA/PEI layers showed 100\% apoptosis and necrosis ratios (i.e., $0 \%$ cell viability) after $24 \mathrm{~h}$, demonstrating that the PDA/PEI/5-Fu layers possessed excellent and continuous anti-cancer function, which was consistent with the PDA/PEI layer reported in the previous work [12]. 


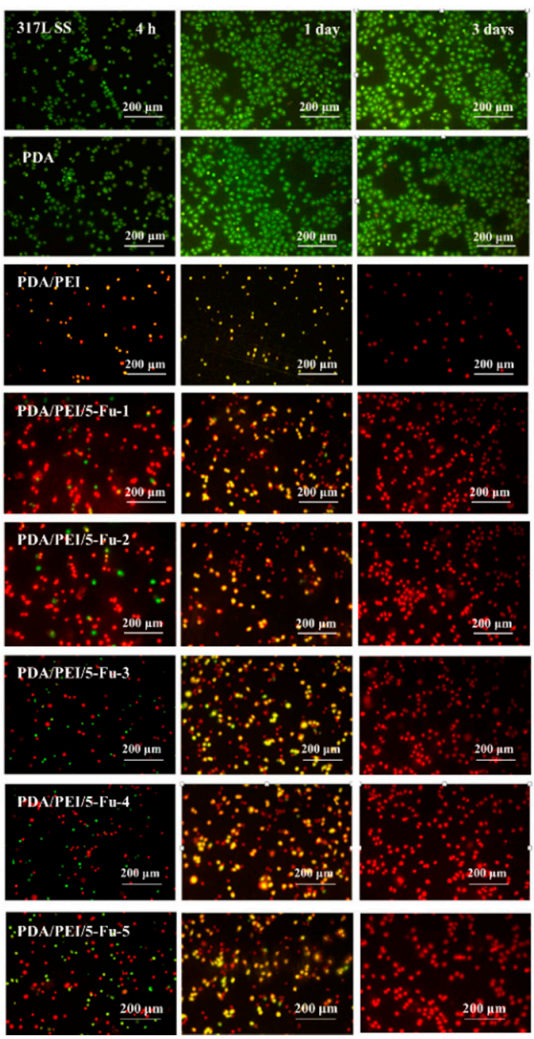

(A)
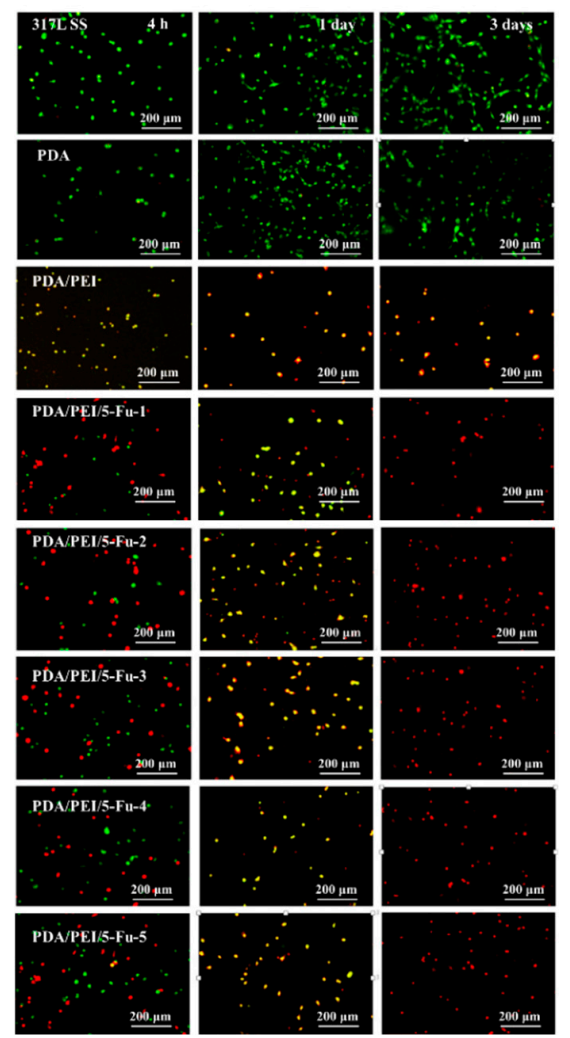

$200.1 \mathrm{ne}$

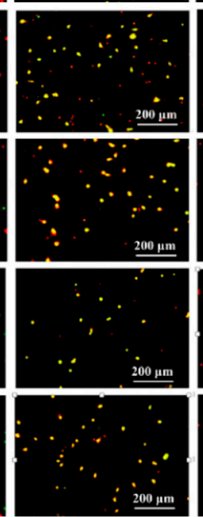

(B)
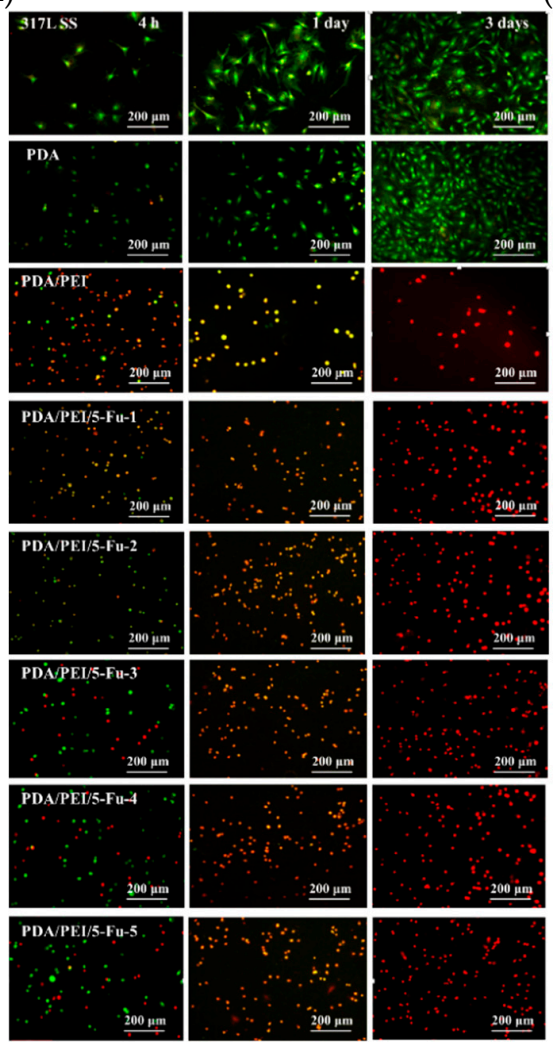

(C)

Figure 8. (A) Eca109, (B) Het-1A and (C) L929 cells apoptosis and necrosis on the PDA/PEI/5-Fu layers and reference surfaces (green intact nucleus: vital cells; dense green areas of chromatin condensation in the nucleus: early apoptosis; dense orange areas of chromatin condensation: late apoptosis; orange intact nucleus: secondary necrosis). 

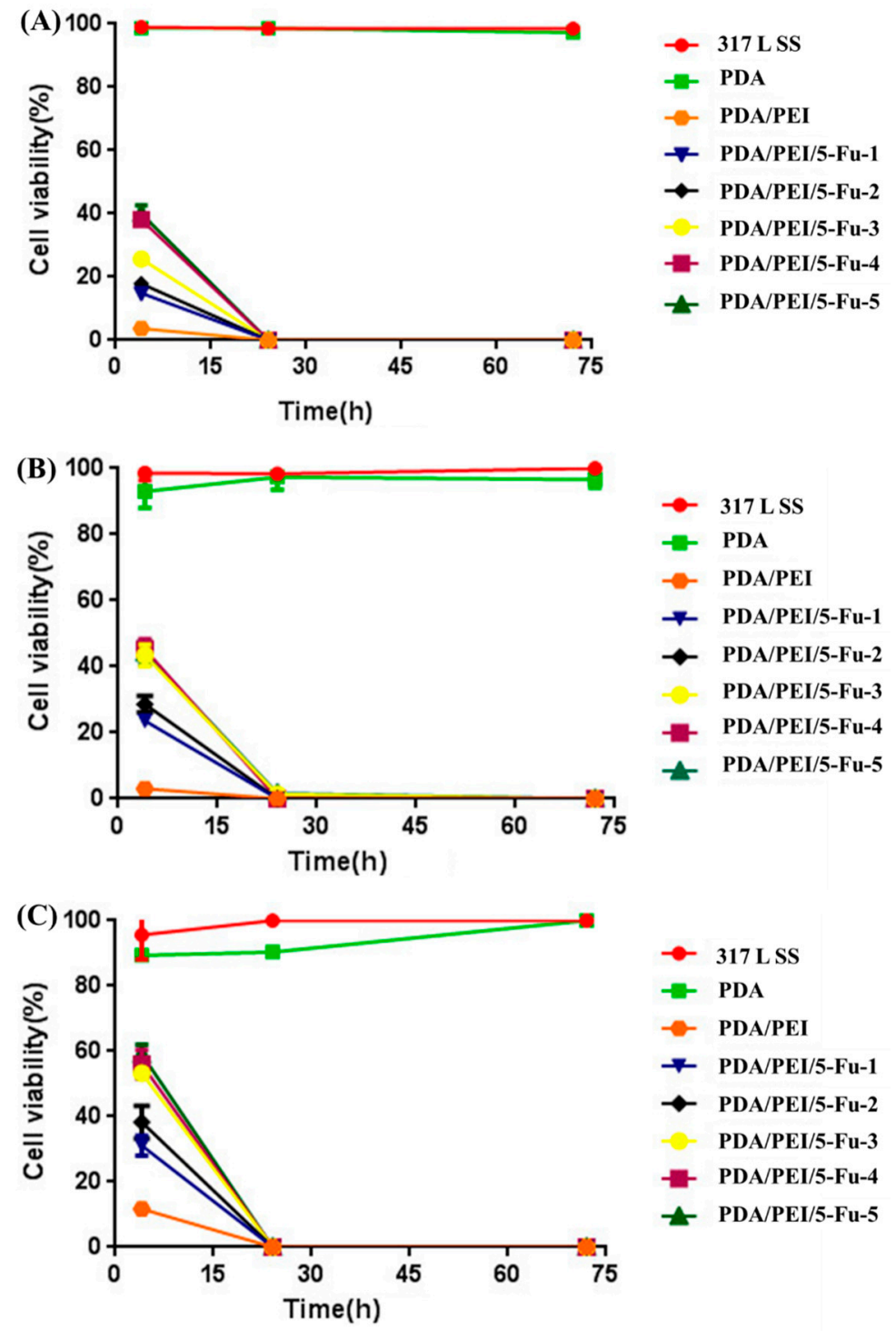

Figure 9. Statistical analysis of (A) Eca109, (B) Het-1A and (C) L929 cells apoptosis and necrosis (by counting cell viability) on the PDA/PEI/5-Fu layers and reference surfaces (mean $\pm \mathrm{SD}, n=3$ ).

\section{Conclusions}

We aimed to develop a drug-eluting layer that provides strong anti-cancer and anti-restenosis functions within a short time for the esophageal stent materials. In this work, the clinical drug 5-Fu was immobilized on to the PDA/PEI modified 317L SS substrate, and the PDA/PEI modified layer was proved to possess sustained anti-cancer function in the previous work. Herein all the $\mathrm{PDA} / \mathrm{PEI} / 5-\mathrm{Fu}$ layers also showed sustained and consistent properties of improving pathological cell (esophageal carcinoma cells, human esophageal epithelial cells, and fibroblast) apoptosis and necrosis on their surface after $24 \mathrm{~h}$. Moreover, the PDA/PEI/5-Fu layers presented a strong ability to promote apoptosis and necrosis of related cells (esophageal carcinoma cells, human esophageal epithelial cells, and fibroblasts) that participated in the restenosis of the esophagus within $12 \mathrm{~h}$ via a drug release test, and this important function did not appear in the PDA/PEI control. In particular, the layers that immobilized $9.6 \pm 0.2 \mu \mathrm{g} / \mathrm{mm}^{2}$ of 5 -Fu (PDA/PEI/5-Fu-1) possessed the best anti-cancer and anti-restenosis function. All these results suggest the promising potential of the PDA/PEI-5-Fu layers for the application on surface modification of the esophageal stent materials. 
Author Contributions: Conceptualization, J.L. and K.Z.; Methodology, K.Z.; Software, Y.B.; Validation, Y.B., R.X. and H.L. (Huiwen Luo); Formal Analysis, J.L.; Investigation, Y.C.; Resources, K.Z.; Data Curation, Y.B.; Writing-Original Draft Preparation, J.L.; Writing-Review \& Editing, J.L.; Visualization, Y.B.; Supervision, F.G.; Project Administration, H.L. (Hongtao Liu); Funding Acquisition, K.Z.

Funding: This research was funded by the Joint Fund for Fostering Talents of National Natural Science Foundation of China and Henan province (U1504310), National Natural Science Foundation of China (NSFC 81471306), Key scientific research projects of higher education institutions in Henan province (16A430030), the Innovative Research Team in Science and Technology of the University of Henan Province (15IRTSTHN022), the Plan for Scientific Innovation Talent of Henan Province (154200510008), China Postdoctoral Science Foundation (2015M582206), and Young Teachers Foundation of Zhengzhou University (No. 32210475) for financial support.

Conflicts of Interest: The authors declare no conflict of interest.

\section{References}

1. Bjelovic, M.; Stojakov, D.; Spica, B.; Velicković, D.; Dragan, G.; Skrobić, O.; Djurasić, L.; Grujić, D.; Pesko, P. Minimally invasive esophagectomy in the treatment of esophageal cancer. Acta Chir. Iugosl. 2011, 58, 27-30. [CrossRef] [PubMed]

2. Chen, M.F.; Yang, Y.H.; Lai, C.H.; Chen, W.C. Outcome of patients with esophageal cancer: A nationwide analysis. Ann. Surg. Oncol. 2013, 20, 3023-3030. [CrossRef] [PubMed]

3. Mulligan, C.R., Jr. Multidisciplinary management of esophageal cancer. Surg. Oncol. Clin. N. Am. 2013, 22, 217-246. [CrossRef] [PubMed]

4. Vleggaar, F.P.; Siersema, P.D. Expandable stents for malignant esophageal disease. Gastrointest. Endosc. Clin. N. Am. 2011, 21, 377-388. [CrossRef] [PubMed]

5. Vermeulen, B.D.; Siersema, P.D. Esophageal stenting in clinical practice: An overview. Curr. Treat. Options Gastroenterol. 2018, 16, 260-273. [CrossRef] [PubMed]

6. Guo, Q.; Guo, S.; Wang, Z. A type of esophageal stent coating composed of one 5-fluorouracil-containing EVA layer and one drug-free protective layer: In vitro release, permeation and mechanical properties. J. Control. Release 2007, 118, 318-324. [CrossRef] [PubMed]

7. Zhu, Y.; Hu, C.; Li, B.; Yang, H.L.; Cheng, Y.S.; Cui, W.G. A highly flexible paclitaxel-loaded poly( $\varepsilon$-caprolactone) electrospun fibrous-membrane-covered stent for benign cardia stricture. Acta Biomater. 2013, 9, 8328-8336. [CrossRef] [PubMed]

8. Tokar, J.L.; Banerjee, S.; Barth, B.A.; Desiletsi, D.J.; Kaul, V.; Kethi, S.R.; Pedrosa, M.C.; Pfau, P.R.; Pleskow, D.K.; Varadarajulu, S. Drug-eluting/biodegradable stents. Gastro Intest. Endosc. 2011, 74, 954-958. [CrossRef] [PubMed]

9. Chen, W.; Shen, Y.; Rong, H.; Lei, L.; Guo, S.R. Development and application of a validated gradient elution HPLC method for simultaneous determination of 5-fluorouracil and paclitaxel in dissolution samples of 5-fluorouracil/paclitaxel-co-eluting stents. J. Pharm. Biomed. Anal. 2012, 59, 179-183. [CrossRef] [PubMed]

10. Dua, K.S. Expandable stents for benign esophageal disease. Gastrointest. Endosc. Clin. N. Am. 2011, 21, 359-376. [CrossRef] [PubMed]

11. Li, J.A.; Wu, F.; Zhang, K.; He, Z.K.; Zou, D.; Luo, X.; Fan, Y.H.; Yang, P.; Zhao, A.S.; Huang, N. Controlling molecular weight of hyaluronic acid conjugated on amine-rich Surface: Towards better multifunctional biomaterials for cardiovascular implants. ACS Appl. Mater. Interfaces 2017, 9, 30343-30358. [CrossRef] [PubMed]

12. Zhang, K.; Bai, Y.X.; Wang, X.F.; Li, Q.; Guan, F.X.; Li, J.A. Surface modification of esophageal stent materials by a polyethylenimine layer aiming at anti-cancer function. J. Mater. Sci. Mater. Med. 2017, 28, 125. [CrossRef] [PubMed]

13. Ohashi, S.; Miyamoto, S.; Kikuchi, O.; Goto, T.; Amanuma, Y.; Muto, M. Recent advances from basic and clinical studies of esophageal squamous cell carcinoma. Gastroenterology 2015, 149, 1700-1715. [CrossRef] [PubMed]

14. Yao, H.; Li, J.A.; Li, N.; Wang, K.B.; Li, X.; Wang, J. Surface modification of cardiovascular stent material-316L SS with estradiol loaded poly(trimethylene carbonate) film for better biocompatibility. Polymers 2017, 9, 598. [CrossRef]

15. Longley, D.B.; Harkin, D.P.; Johnston, P.G. 5-fluorouracil: Mechanisms of action and clinical strategies. Nat. Rev. Cancer 2003, 3, 330-338. [CrossRef] [PubMed] 
16. Wu, F.; Li, J.A.; Zhang, K.; He, Z.K.; Yang, P.; Zou, D.; Huang, N. Multi-functional coating based on hyaluronic acid and dopamine conjugate for potential application on surface modification of cardiovascular implanted devices. ACS Appl. Mater. Interfaces 2016, 8, 109-121. [CrossRef] [PubMed]

17. Liu, W.; Li, X.L.; Wong, Y.S.; Zheng, W.J.; Zhang, Y.B.; Cao, W.Q.; Chen, T.F. Selenium nanoparticles as a carrier of 5-fluorouracil to achieve anticancer synergism. ACS Nano 2012, 6, 6578-6591. [CrossRef] [PubMed]

18. Li, J.A.; Zhang, K.; Xu, Y.; Chen, J.; Yang, P.; Zhao, Y.C.; Zhao, A.S.; Huang, N. A novel co-culture models of human vascular endothelial cells and smooth muscle cells by hyaluronic acid micro-pattern on titanium surface. J. Biomed. Mater. Res. Part A 2014, 102A, 1950-1960. [CrossRef] [PubMed]

19. Li, J.A.; Li, G.C.; Zhang, K.; Liao, Y.Z.; Yang, P.; Maitz, M.F.; Huang, N. Co-culture of vascular endothelial cells and smooth muscle cells by hyaluronic acid micro-pattern on titanium surface. Appl. Surf. Sci. 2013, 273, 24-31. [CrossRef]

20. Zhang, K.; Shi, Z.Q.; Zhou, J.K.; Xing, Q.; Ma, S.S.; Li, Q.H.; Zhang, Y.T.; Yao, M.H.; Wang, X.F.; Li, Q.; et al. Potential application of an injectable hydrogel scaffold loaded with mesenchymal stem cells for treating traumatic brain injury. J. Mater. Chem. B 2018, 6, 2982-2992. [CrossRef]

21. Li, J.A.; Qin, W.; Zhang, K.; Wu, F.; Yang, P.; He, Z.K.; Zhao, A.S.; Huang, N. Controlling mesenchymal stem cells differentiate into contractile smooth muscle cells on a $\mathrm{TiO}_{2}$ micro/nano interface: Towards benign pericytes environment for endothelialization. Colloids Surf. B Biointerfaces 2016, 145, 410-419. [CrossRef] [PubMed]

22. Li, J.A.; Zou, D.; Zhang, K.; Luo, X.; Yang, P.; Jing, Y.Y.; Zhang, Y.X.; Cui, G.L.; Huang, N. Strong Multi-functions based on conjugating chondroitin sulfate on amine-rich surface direct vascular cells fate for cardiovascular implanted devices. J. Mater. Chem. B 2017, 5, 8299-8313. [CrossRef]

23. Li, J.A.; Yang, P.; Zhang, K.; Ren, H.L.; Huang, N. Preparation of $\mathrm{SiO}_{2} / \mathrm{TiO}_{2}$ and $\mathrm{TiO}_{2} / \mathrm{TiO}_{2}$ micropattern and their effects on platelet adhesion and endothelial cell regulation. Nucl. Instrum. Methods Phys. Res. B 2013, 307, 575-579. [CrossRef]

24. Yang, Y.; Qi, P.; Ding, Y.; Maitz, M.F.; Yang, Z.; Tu, Q.; Xiong, K.; Leng, Y.; Huang, N. A biocompatible and functional adhesive amine-rich coating based on dopamine polymerization. J. Mater. Chem. B 2015, 3, 72-81. [CrossRef]

25. Lee, H.; Lee, Y.; Statz, A.R.; Rho, J.; Park, T.G.; Messersmith, P.B. Substrate independent layer by layer assembly by using messel-adhesive-inspired polymers. Adv. Mater. 2008, 20, 1619-1623. [CrossRef] [PubMed]

26. Wu, J.J.; Li, J.A.; Wu, F.; He, Z.K.; Yang, P.; Huang, N. Effect of micropatterned $\mathrm{TiO}_{2}$ nanotubes thin film on the deposition of endothelial extracellular matrix: For the purpose of enhancing surface biocompatibility. Biointerphases 2015, 10, 04A302. [CrossRef] [PubMed]

27. Li, J.A.; Zhang, K.; Wu, J.J.; Zhang, L.J.; Yang, P.; Tu, Q.F.; Huang, N. Tailoring of the titanium surface by preparing cardiovascular endothelial extracellular matrix layer on the hyaluronic acid micro-pattern for improving biocompatibility. Colloids Surf. B Biointerfaces 2015, 128, 201-210. [CrossRef] [PubMed]

28. Su, H.; Xue, G.N.; Ye, C.Y.; Wang, Y.; Zhao, A.S.; Huang, N.; Li, J.A. The effect of anti-CD133/fucoidan bio-coatings on hemocompatibility and EPC capture. J. Biomater. Sci. Polym. Ed. 2017, 28, $2066-2081$. [CrossRef] [PubMed]

29. Zhang, K.; Wang, X.F.; Guan, F.X.; Li, Q.; Li, J.A. Immobilization of Ophiopogonin D on stainless steel surfaces for improving surface endothelialization. RSC Adv. 2016, 6, 113893-113898. [CrossRef]

30. Balkwill, F.; Mantovani, A. Inflammation and cancer: Back to Virchow? Lancet 2001, 357, 539-545. [CrossRef]

31. Zhu, F.; Willette-Brown, J.; Song, N.Y.; Lomada, D.; Song, Y.; Xue, L.; Gray, Z.; Zhao, Z.; Davis, S.R.; Sun, Z.; et al. Autoreactive T cells and chronic fungal infection drive esophageal carcinogenesis. Cell Host Microbe 2017, 21, 478-493.e7. [CrossRef] [PubMed]

32. Chen, H.L.; Shen, W.Q.; Liu, K. Radioactive self-expanding stents for palliative management of unresectable esophageal cancer: A systematic review and meta-analysis. Dis. Esophagus 2017, 30, 1-16. [CrossRef] [PubMed]

33. Chen, H.; Ni, Z.; Jing, D.; He, L.; Qiao, L.; Liu, L.; Wei, X.; Jiang, M.; Tang, S.; Xu, H. Novel stent in the palliation of malignant esophageal strictures: A retrospective study. Dis. Esophagus 2017, 30, 1-5. [CrossRef] [PubMed] 
34. Zhao, P.; Zhang, M.Q.; Zhang, Y.L.; Guo, Y.C.; Zhao, Y.L.; Wu, Q.W.; Zhao, A.Y.; Zhang, X.Z. Application of esophageal irradiation stents coated with I-125 particles in advanced esophageal cancer. J. BUON 2017, 22 , 265-269. [PubMed]

35. Gan, Z.; Jing, J.; Zhu, G.Y.; Qin, Y.L.; Teng, G.J.; Guo, G.H. Preventive effects of I-125 seeds on benign restenosis following esophageal stent implantation in a dog model. Mol. Med. Rep. 2015, 11, 3382-3390. [CrossRef] [PubMed]

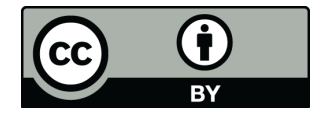

(C) 2018 by the authors. Licensee MDPI, Basel, Switzerland. This article is an open access article distributed under the terms and conditions of the Creative Commons Attribution (CC BY) license (http://creativecommons.org/licenses/by/4.0/). 